\title{
Mental Rotation in Unipolar Major Depression
}

\author{
M.A. Rogers ${ }^{1}$, J.L. Bradshaw ${ }^{1}$, J.G. Phillips ${ }^{1}$, E. Chiu ${ }^{2}$, C. Mileshkin ${ }^{3}$, and K. Vaddadi ${ }^{3}$ \\ ${ }^{1}$ Neuropsychology Research Unit, Department of Psychology, Monash University, Clayton, Vic., Australia, \\ ${ }^{2}$ Academic unit for Psychiatry of Old Age, University of Melbourne, Normanby House, St. George's Hospital, Vic., \\ Australia, and ${ }^{3}$ Department of Psychiatry, Maroondah Hospital, Vic., Australia
}

\begin{abstract}
Mental rotation (MR) performance may be used as an index of mental slowing or bradyphrenia, and may reflect, in particular, speed of motor preparation. MR was employed with a sample of both melancholic $(n=8)$ and non-melancholic $(n=9)$ unipolar depressed patients and healthy controls $(n=10)$ to determine if motor slowing associated with depression might be reflected in slowed motor preparation (as reflected in slope of the MR function) independent of actual motor slowing (overall response time). Both melancholic and non-melancholic patients showed a generalised slowing relative to controls, perhaps reflecting bradykinesia and akinesia. This effect was significantly greater in the melancholic group than in the non-melancholic group. Relative to both the controls and the non-melancholic groups, the melancholic patients showed a progressive slowing with increasing angle of orientation indicating a specific slowing of MR. This deficit suggests a role of slowed motor planning in the psychomotor retardation of patients with melancholic depression.
\end{abstract}

Psychomotor disturbance in major depression may not be simply a secondary reaction to impaired mood and motivation, but rather a reflection of underlying neurophysiological deficit (Austin \& Mitchell, 1996; Rogers, 1986). Such impairment may also be an important and possibly defining marker of melancholic depression in particular (Nelson \& Charney, 1981; Parker et al., 1995).

Clinically, psychomotor retardation (PMR) in melancholic depression may appear Parkinsonian in nature, particularly with respect to the negative signs of Parkinson's disease (PD) (Austin \& Mitchell, 1996; Fleminger, 1991). There is some empirical behavioural evidence to support clinical observation, with indications of a characteristically Parkinsonian reliance on external cueing in melancholic but not in non-melancholic patients (Rogers et al., 2000), suggestive of a failure of internal cueing to self-initiate movement. Evidence of similar force inefficiencies in the two disorders, PD and melancholic depression, have also been reported (Sachdev \& Annis, 1994).

Biological evidence of an underlying neuropathology common to both PMR and PD include possible dopaminergic deficits (Ebert et al., 1996; Mann \& Kapur, 1995; Shah et al., 1997), abnormal Bereitschaftspotential (Khanna, Mukundan, \& Channabasavanna, 1989), and functional and in some cases structural, abnormalities of the basal ganglia (BG) (Hussain et al., 1991; Krishnan et al., 1992; O'Brien et al., 1996). Any motor slowing in melancholic depression, however, is likely to stem from a functional, rather than a structural deficit, given the typically good response to somatic treatment; indeed psychomotor signs may be among the first to remit (Sobin \& Sackheim, 1997).

While there are indications of a PD-like cuedependent slowing in melancholic depression, there may also be an element of generalised slowing (Rogers et al., 2000). Cornell, Suarez,

Address correspondence to: M.A. Rogers, Neuropsychology Research Unit, Department of Psychology, Monash University, Clayton, Vic. 3168, Australia. Tel.: +1-613-9905-3956. Fax: +1-613-9905-3948. E-mail: mark.rogers @ sci.monash.edu.au

Accepted for publication: May 16, 2001. 
and Berent (1984) found that melancholic (but not non-melancholic) patients exhibited a cognitive component (slowing) on a motor task. Bradyphrenia may, therefore, play a role in PMR, specifically in terms of slowed motor preparation. Indeed, bradyphrenia in PD and PMR in depression have both been attributed to impaired dopaminergic function (Rogers, Lees, Smith, Trimble, \& Stern, 1987).

One way of assessing any role of bradyphrenia in slowed motor preparation in PMR may be via use of mental rotation. Mental rotation involves the mental re-orientation of an internalised image of a stimulus figure until it achieves congruence with either a physical comparison figure, or a memory-stored comparison figure. Numerous studies have reported a positive linear relationship between the angular difference between the two figures and the time taken for completion of the task; this suggests that the mental image is indeed rotated in an analogue manner similar to physical rotation of actual objects (Cooper \& Shepard, 1973; Shepard \& Cooper, 1982). Electrophysiological recordings from primates suggest that neurons in the motor cortex describe a population vector which shifts in an analogue manner consistent with this hypothesis (Georgeopoulos, Lurito, Petrides, Schwartz, \& Massey, 1989; Lurito, Georgakopoulos, \& Georgeopoulos, 1991; but see Cisek $\&$ Scott, 1999).

Mental rotation may be viewed as a cognitive analogue of real movement and likely taps cortical regions and mechanisms involved in motor preparation, particularly motor anticipation, that is, anticipation of the likely consequences of a motor action (Wohlschläger \& Wohlschläger, 1998; Wexler, Kosslyn, \& Berthoz, 1998). As such, mental rotation may, therefore, be considered a mental analogue of bradykinesia rather than as a measure of global bradyphrenia.

The present study employed a mental rotation paradigm. Patients with unipolar major depression (melancholic and non-melancholic), and healthy controls, performed a task to decide whether a numerical symbol was in its normal or mirror image form. When the stimulus appeared rotated from vertical, a procedure necessary for making the subsequent comparison, participants were encouraged to mentally 'rotate' the stimulus back to vertical, and then decide whether the stimulus was the normal or the mirror form. A button press indicated the decision. If the motor slowing in PMR is partly due to slowed motor preparation, a progressively-increasing reaction time with increasing angle of orientation should be particularly marked in the melancholic group, relative to both the control and the non-melancholic group.

\section{METHODS}

\section{Participants}

Participants were 17 patients with unipolar major depression (DSM IV) and 10 age-matched controls. Written informed consent was obtained from all participants.

Exclusion criteria were: neurological impairment, dementia (i.e., Minimental State Exam scores below 23), musculo-skeletal pathology and poor corrected vision. Controls were without psychiatric or neurological history. The patient group was divided into melancholic and non-melancholic subgroups on the basis of the CORE measure for psychomotor disturbance (8 melancholic, 9 nonmelancholic). In the melancholic group were 4 females and 4 males. In the non-melancholic group there were 5 females and 4 males. A CORE rating of 8 or greater was considered an indication of melancholic depression (Parker \& Hadzi-Pavlovic, 1996). The CORE measure has been found to predict response to ECT (Hickie, Mason, Parker, \& Brodaty, 1996) and to correlate significantly with post dexamethasone cortisol concentration (Mitchell et al., 1996).

The groups did not differ significantly in Age (control group $M=50$, melancholic $M=43$, nonmelancholic $M=57), F(2,24)=2.169, p>.1$; or by NART (Nelson, 1982) estimate of premorbid IQ (controls $M=114$, melancholic $M=110$, non-melancholic $M=117), F(2,22)=1.672, p>.2$.

The melancholic $(M=29)$ and non-melancholic $(M=20)$ groups did not differ significantly in their mean Beck Depression Inventory score, $M(1,15)=$ $4.065, p>.05$.

The melancholic group $(M=14)$ did, however, as expected, score significantly more highly than the non-melancholic group $(M=3.4)$ on the CORE measure of psychomotor disturbance, $F(1,15)=$ $73.451, p<.001$.

Thirteen patients were taking standard antidepressant medications at the time of testing; four patients were not medicated then (see Table 1). 
Table 1. Clinical Details for Depressed Patient Group.

\begin{tabular}{|c|c|c|c|c|c|c|}
\hline Patient & Age & Sex & CORE & Beck & NART & Medication (daily dose) \\
\hline 1 & 52 & $\mathrm{~F}$ & 12 & 35 & 120 & $\begin{array}{l}\text { Trifluoperazine Hydrochloride } 1 \mathrm{mg} \\
\text { Venlafaxine Hydrochloride } 225 \mathrm{mg}\end{array}$ \\
\hline 2 & 42 & M & 9 & 25 & 106 & Venlafaxine Hydrochloride $150 \mathrm{mg}$ \\
\hline 3 & 31 & $\mathrm{~F}$ & 10 & 33 & * & N/A \\
\hline 4. & 43 & M & 14 & 35 & 111 & Venlafaxine Hydrochloride $225 \mathrm{mg}$ \\
\hline 5 & 33 & $\mathrm{~F}$ & 27 & 36 & 108 & Venlafaxine Hydrochloride $300 \mathrm{mg}$ \\
\hline 6 & 31 & M & 14 & 24 & 110 & Sertraline Hydrochloride $50 \mathrm{mg}$ \\
\hline 7 & 33 & M & 12 & 23 & 110 & $\begin{array}{l}\text { Venlafaxine Hydrochloride } 300 \mathrm{mg} \\
\text { Zopiclone } 7.5 \mathrm{mg}\end{array}$ \\
\hline 8 & 72 & $\mathrm{~F}$ & 15 & 18 & 115 & Sertraline Hydrochloride $100 \mathrm{mg}$ \\
\hline 9 & 41 & M & 3 & 10 & 124 & $\begin{array}{l}\text { Venlafaxine Hydrochloride } 150 \mathrm{mg} \\
\text { Mianserin Hydrochloride } 10 \mathrm{mg}\end{array}$ \\
\hline 10 & 48 & $\mathrm{~F}$ & 1 & 32 & 122 & $\begin{array}{l}\text { Venlafaxine Hydrochloride } 375 \mathrm{mg} \\
\text { Lithium Carbonate } 250 \mathrm{mg}\end{array}$ \\
\hline 11 & 72 & $\mathrm{~F}$ & 1 & 9 & 119 & N/A \\
\hline 12 & 52 & $\mathrm{M}$ & 3 & 34 & 107 & Nefazodone $400 \mathrm{mg}$ \\
\hline 13 & 83 & M & 6 & 11 & 121 & Fluoxetine Hydrochloride $20 \mathrm{mg}$ \\
\hline 14 & 70 & $\mathrm{~F}$ & 6 & 14 & 119 & N/A \\
\hline 15 & 45 & M & 4 & 20 & * & Venlafaxine Hydrochloride $75 \mathrm{mg}$ \\
\hline 16 & 50 & $\mathrm{~F}$ & 2 & 20 & 121 & N/A \\
\hline 17 & 31 & $\mathrm{~F}$ & 5 & 31 & 114 & $\begin{array}{l}\text { Venlafaxine Hydrochloride } 75 \mathrm{mg} \\
\text { Alprazolam } 1 \mathrm{mg} \\
\text { Trifluoperazine Hydrochloride } 1 \mathrm{mg}\end{array}$ \\
\hline
\end{tabular}

Note. * Non-native speaker of English.

\section{Apparatus}

Participants viewed experimental stimuli on a Toshiba notebook IBM-compatible computer with a colour active screen. Responses were made via micro-switches, one switch for each hand.

A set of stimulus cards depicting the numerals (2 and 7) and their left-right mirror-reversed versions were used to help explain the task.

\section{Procedure}

Each trial consisted of presentation of a fixation point followed by a single numeral (either 2 or 7 ) at the centre of the screen. Each numeral could appear either upright or at one of the following degrees anticlockwise from vertical, $60^{\circ}, 120^{\circ}, 180^{\circ}$, or $300^{\circ}$; it could also be either in the normal or mirrorreversed form. Numerals were $5 \mathrm{~cm}$ high and $2.5 \mathrm{~cm}$ wide, and were green on a black background.

A button press from the investigator initiated each trial. A centred fixation point $2 \mathrm{~mm}$ in diameter appeared for $1200 \mathrm{~ms}$, followed by blank screen for $1000 \mathrm{~ms}$. The stimulus numeral appeared for $400 \mathrm{~ms}$, after which the screen was blank until the participant made a response or until timed-out after $4000 \mathrm{~ms}$. Participants were required to indicate whether the numeral was in its normal (respond with right hand) or in mirror (respond with left hand) form. Participants were asked to respond not only as quickly but also as accurately as possible. Responses shorter than $100 \mathrm{~ms}$ or longer than $4000 \mathrm{~ms}$ were discarded, but those trials were not repeated. Reaction time (RT) and accuracy were recorded automatically for each trial.

Participants were familiarised with the normal and mirror-image version of the two numerals via stimulus cards. These were shown to the participant at various angles from upright and then rotated to the normal upright position, whereupon the participant was to indicate whether the stimulus was of the normal or mirror-image form. This helped to explain the requirements of the task, and to encourage use of mental rotation as the dominant strategy.

Participants then received 48 practice trials, 24 for each numeral. Feedback employing stimulus cards where necessary was provided after each trial. Practice continued until the participants achieved an accuracy criterion of at least $75 \%$. All participants received an ensemble of 7's and 2's. Half of the presentations of numeral and orientation were of the normal and half were of the mirror-reversed form. Order of presentation of the numeral and the type was randomised. 


\section{RESULTS}

The mean reaction times were analysed by threeway mixed-model ANOVA with factors of Group (melancholic, non-melancholic, controls), Version (normal, mirror) and Angle of Orientation $\left(0^{\circ}, 60^{\circ}, 120^{\circ}, 240^{\circ}, 300^{\circ}\right)$. All analyses were planned comparisons.

There was a significant effect of Group with melancholic patients $(M=1386 \mathrm{~ms}, S D=399)$ being slower overall than both non-melancholic patients $(M=1095 \mathrm{~ms}, S D=376)$ and the control group $(M=831 \mathrm{~ms}, S D=296), F(2,24)=13.54$, $p<.01$. (See Fig. 1 Note, data at $0^{\circ}$ are repeated at $360^{\circ}$ for aesthetic purposes). Sub-analysis shows that the non-melancholic group was also significantly slower than the control group, $F(1,17)=$ $6.310, p<.05$.

The interaction of Group X Angle of orientation was significant, $F(10,120)=1.998, p<.05$. Subanalysis indicates that the melancholic $[F(5,80)=$ $2.855, p<.05]$, but not the non-melancholic $[F(5,85)=0.099, p>.9]$ patients, slowed progressively with increasing angle of orientation relative to the controls. Melancholic patients also progres- sively slowed relative to the non-melancholic patients, $F(5,75)=2.692, p<.05$. Thus the melancholic group slowed significantly in their mental rotation performance relative to both the controls and the non-melancholic group.

There was also a significant interaction of Angle of Orientation $\mathrm{X}$ Version with reaction times generally becoming longer from $0^{\circ}$ to $180^{\circ}$ before shortening again from $180^{\circ}$ to $300^{\circ}$; thus reaction times slowed as a function of the angular distance from vertical, the effect being more pronounced for mirror than for normal stimuli, $F(5,120)=3.333, p<.025$.

The error data were analysed by three-way ANOVA with the same factors as above. Although both patient groups [melancholic $M=8.9(S D=$ $6.7)$, non-melancholic $M=9(S D=8.7)]$ committed more errors than did the controls $M=4.6$ $(S D=3.9)$, the effect of Group was non-significant, $F(2,24)=1.380, p>.05$. Nor were there any significant interactions.

There was a significant positive correlation (Spearman's rho) between CORE scores and mean RT on the mental rotation task for the depressed patients, indicating that higher CORE

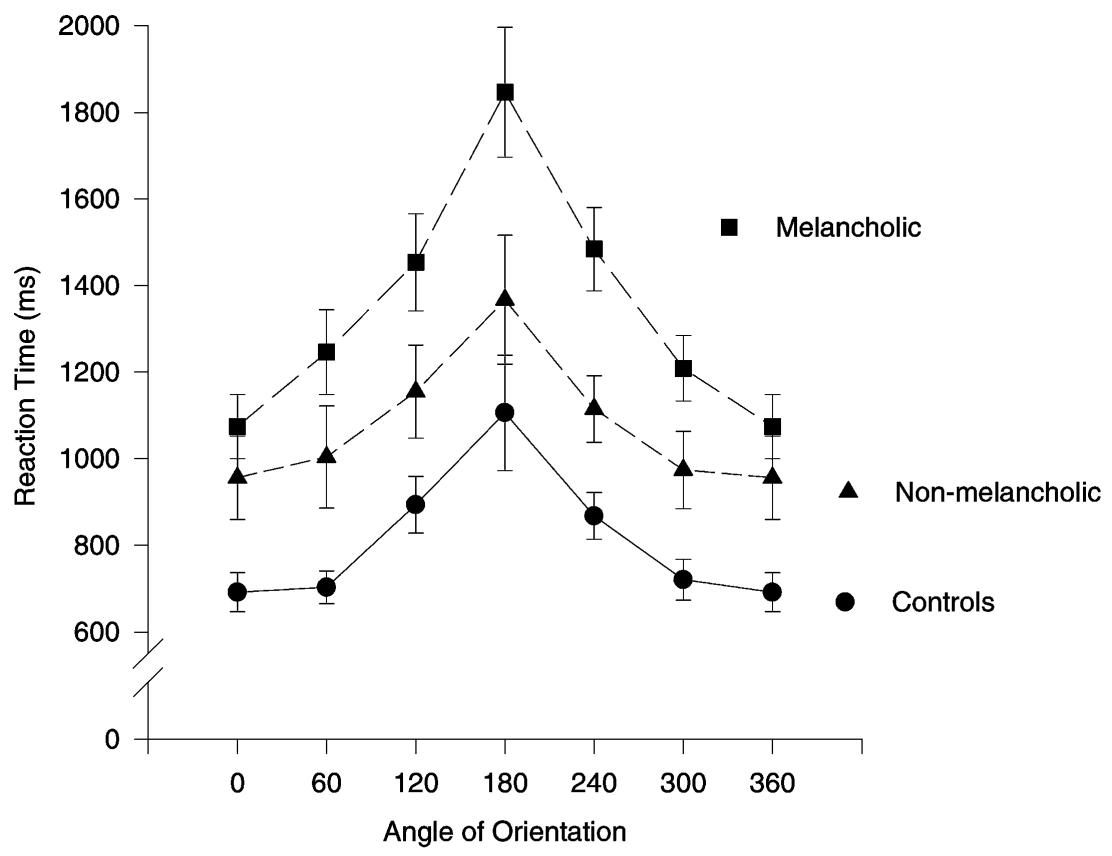

Fig. 1. Mean reaction time (ms) for melancholic and non-melancholic depressed patients and controls, at each angle of orientation, collapsed across stimulus version (mirror/normal). 
scores were associated with a greater degree of motor slowing, $r(16)=.603, p<.025$.

There were too few unmedicated patients to make meaningful comparisons between those on and off medication.

\section{DISCUSSION}

This study assessed the mental rotation performance of patients with unipolar major depression to determine the presence and extent of any bradyphrenia that might contribute to motor slowing. Non-melancholic patients served to control for symptoms of depressions other than those involving marked psychomotor disturbance.

The melancholic group showed a pattern of progressively increasing slowing with increasing angle of orientation which was greater than that shown by either the controls or the non-melancholic group. The non-melancholic group, though overall slower than controls, showed a pattern of progressive slowing similar in slope to that of the control group. The melancholic, but not the nonmelancholic group, therefore, showed a specific deficit of mental rotation.

The overall slowing, or the increased intercept of the function, for the two patient groups may reflect bradykinesia and akinesia. Such deficits would produce a constant increase in reaction time independent of the angle of stimulus orientation. The significantly greater slowing of the melancholic relative to the non-melancholic group supports past findings of Parkinsonian motor deficits in melancholic depression (Rogers et al., 2000; Sachdev \& Annis, 1996). The lesser slowing of the non-melancholic group might reflect a much muted Parkinsonian slowing, or, alternatively, simply reduced motivation and volition. In the latter case, an element of the slowing of the melancholic group is also likely to be due to motivational deficits.

The melancholic but not the non-melancholic group showed an increased slope relative to controls indicating a progressive slowing with increasing angle of orientation. This reflects bradyphrenia. Wolschläger and Wolschläger (1998) and Wexler et al. (1998) have indicated that the mechanisms underlying MR appear to be the same as those involved in the preparation of actual movement. The bradyphrenia identified in these melancholic patients may, therefore, be specifically related to motor preparation rather than a global mental slowing. The possible specificity of MR as a measure of speed of motor preparation is further supported by the findings of Dominey et al. (1995), who had hemi-Parkinson's patients mentally rotate drawings of hands to determine whether each was a left or right. These patients were slow only for decisions representing the 'affected' (right) hand. For the 'unaffected' (left) hand, the patients were actually faster than the controls; this should not occur if mental rotation were a measure of global bradyphrenia.

The observed MR deficit in melancholic patients suggests an underlying slowing of motor preparation, which may contribute to PMR. Difficulties in motor preparation in conjunction with Parkinsonian deficits in motor initiation and execution implicate involvement of the motor circuit in PMR, the former reflecting the prefrontal, and the latter the subcortical poles of the circuit, respectively.

\section{ACKNOWLEDGMENTS}

We wish to sincerely thank Prof. Gordon Parker and Assoc. Prof. Phillip Mitchell of the Mood Disorders Unit, Prince Henry Hospital and The University of New South Wales for their assistance with the CORE rating scale, and Bob Wood, Frank Devlin, Truong Nguyen and Mike Durham for designing and maintaining the apparatus and software.

\section{REFERENCES}

Austin, M.-P., \& Mitchell, P. (1996). Melancholia as a neurological disease. In G. Parker \& D. HadziPavlovic (Eds.), Melancholia: A disorder of movement and mood (pp. 223-236). Cambridge: Cambridge University Press.

Cisek, P., \& Scott, S.H. (1999). An alternative interpretation of population vector rotation in macaque motor cortex. Neuroscience Letters, 272, 1-4.

Cooper, L.A., \& Shepard, R.N. (1973). Chronometric studies of the rotation of mental images. In W.G. Chase (Ed.), Visual information processing. New York: Academic Press. 
Cornell, D.G., Suarez, R., \& Berent, S. (1984). Psychomotor retardation in melancholic and non-melancholic depression: Cognitive and motor components. Journal of Abnormal Psychology, 93, 150-157.

Dominey, P., Decety, J., Broussolle, E., Chazot, G., \& Jeannerod, M. (1995). Motor imagery of a lateralized sequential task is asymmetrically slowed in hemi-Parkinson's patients. Neuropsychologia, 33, 727-741.

Ebert, D., Feistel, H., \& Barocka, A. (1996). Effects of sleep deprivation on the limbic system and the frontal lobes in affective disorders: A study with Tc99m-HMPAO SPECT. Psychiatric Research: Neuroimaging, 40, 247-151.

Fleminger, S. (1991). Depressive motor retardation. International Journal of Geriatric Psychiatry, 6, $459-468$.

Georgeopoulos, A.P., Lurito, J.T., Petrides, M., Schwartz, A.B., \& Massey, J.T. (1989). Mental rotation of the neuronal population vector. Science, 243, 234-236.

Hickie, I., Mason, C., Parker, G., \& Brodaty, H. (1996). Prediction of ECT response: Validation of a refined sign-based (CORE) system for defining melancholia. British Journal of Psychiatry, 169, 68-74.

Hussain, M.M., McDonald, W.M., Doraiswarmy, P.M., Figiel, G.S., Na, C., Escalona, R., Boyko, O., Nemeroff, C.B., \& Krishnan, K.R.R. (1991). A magnetic resonance imaging study of putamen nuclei in major depression. Psychiatric Research: Neuroimaging, 40, 95-99.

Khanna, S., Mukundan, C.R., \& Channabasavanna, S.M. (1989). Bereitschaftpotential in melancholic depression. Biological Psychiatry, 26, 526-529.

Krishnan, K.R.R., McDonald, W.M., Escalona, P.R., Doraiswarmy, P.M., Na, C., Hussain, M.M., \& Figiel, G.S. (1992). Magnetic resonance imaging of the caudate nuclei in depression: Preliminary observations. Archives of General Psychiatry, 49, 553-557.

Lurito, J.T., Georgakopolous, T., \& Georgeopolous, A.P. (1991). Cognitive spatial-motor processes. 7. The making of movements at an angle from a stimulus direction: Studies of motor cortical activity at the single cell and population levels. Experimental Brain Research, 87, 562-580.

Mann, J.J., \& Kapur, S. (1995). A dopaminergic hypothesis of major depression. Clinical Neuropharmacology, 18 (Suppl. 1), S57-S65.

Mitchell, P., Hadzi-Pavlovic, D., Parker, G., Hickie, I., Wilhelm, K., Brodaty, H., \& Boyce (1996).
Depressive psychomotor disturbance, cortisol, and dexamethasone. Biological Psychiatry, 40, 941950.

Nelson, J.C., \& Charney, D.S. (1981). The symptoms of major depressive illness. American Journal of Psychology, 138, 1-3.

Nelson, H.E. (1982). National adult reading test (NART) test manual. Windsor, UK: NFER: Nelson.

O’Brien, J., Desmond, P., Ames, D., Schweitzer, I., Harrigan, S., \& Tress, B. (1996). A magnetic resonance imaging study of white matter lesions in depression and Alzeimer's disease. British Journal Psychiatry, 168, 477-485.

Parker, G., \& Hadzi-Pavlovic, D. (1996). Development and structure of the CORE system. In G. Parker \& D. Hadzi-Pavlovic (Eds.), Melancholia: A disorder of movement and mood (pp. 223-236). Cambridge: Cambridge University Press.

Rogers, D. (1986). Bradyphrenia in Parkinsonism: A historical review. Psychological Medicine, 16, 257265.

Rogers, D., Lees, A.J., Smith, E., Trimble, M., \& Stern, G.M. (1987). Bradyphrenia in Parkinson's disease and psychomotor retardation in depressive illness. Brain, 110, 761-776.

Rogers, M.A., Bradshaw, J.L., Phillips, J.G., Chiu, E., Vaddadi, K., Presnel, I., \& Mileshkin, C. (2000). Parkinsonian motor characteristics in unipolar major depression. Journal of Clinical and Experimental Neuropsychology, 22, 232-244.

Sachdev, P., \& Annis, A.M. (1994). Slowness of movement in melancholic depression. Biological Psychiatry, 35, 253-262.

Shah, P.J., Ogilvie, A.D., Goodwin, G.M., \& Ebmeier, K.P. (1997). Clinical and psychometric correlates of Dopamine D-2 binding in depression. Psychological Medicine, 27, 1247-1246.

Shepard, R.N., \& Cooper, L.A. (1982). Mental images and their transformations. Cambridge, MA: MIT Press.

Sobin, C., \& Sackheim, H.A. (1997). Psychomotor symptoms of depression. American Journal of Psychiatry, 154, 4-17.

Wexler, M., Kosslyn, S.M., \& Berthoz, A. (1998). Motor processes in mental rotation. Cognition, 68, 77-94.

Wohlschläger, A., \& Wohlschläger, A. (1998). Mental and manual rotation. Journal of Experimental Psychology: Human Perception and Performance, 24, 397-412. 